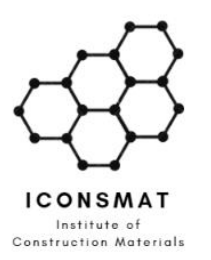

Content list available at ICONSMAT

Journal of Construction Materials

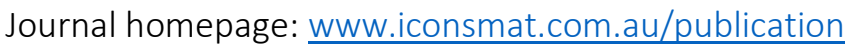

Article history:

Received 27 January 2021

Received in revised form

7 March 2021

Accepted 23 March 2021

Available online

2 April 2021

\title{
Publicizing construction firms by cryptocurrency
}

\author{
Farid Sartipi ${ }^{1 *}$ \\ 1* Corresponding author: E: farid.sartipi@iconsmat.com.au; Institute of Construction Materials
}

\begin{abstract}
Growth as an inevitable human nature roots even in our business operation. Private entities, similarly, in seek of expansion and maybe more influence over their area of expertise, decide to go public in a certain point of time. The timing to move from private to public, indeed, is a critical factor in the future success of the business. In the traditional capitalist structure of this move, small private companies, which are defined by the Australian Securities and Investments Commission as those entities with consolidated revenue of less than $\$ 50$ million per year, choose between sellout to a parent firm or Initial Public Offering (IPO). Both options have their own advantages and disadvantages. Yet, they are both complex, highly regulated, costly, and frustrating which are truly major drawbacks for small entities. Failure to go public caused by these drawbacks results in death of small businesses and loss of jobs which is followed by terrible socio-economic consequences. To avoid the conventional frustrating publicity of the private firms, in this article, utilization of cryptocurrency as the modern financial instrument is discussed. Digital currencies enable fast transition, globalization, grassroot economy, and social justice.
\end{abstract}

DOI: $\underline{10.36756 / J C M . v 2.3 .1}$ (C2021 Institute of Construction Materials

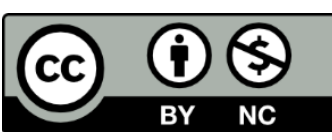

\section{Keywords}

Public firm; Sellout and IPO; Cryptocurrency; Grassroot economy 


\section{Introduction}

After a few years of operation as private entities, construction companies with the aim of growth and wider economic benefits tend to acquire financial instruments [1]. In the traditional capitalist system of governance, central federal banks rule the finances in the economy. Stock markets in conjunction with federal banks issue financial instruments such as shares, dividends, options, future contracts, etc. for registered public companies. This registration process and the high level of upper hand domination on the economy is proved to be harmful which often cause inequality and widen the gap between the poor and wealthy in the society. [2]. Concentration of power that results from the centralized financial system leads the society to decay as it has been observed numerous times throughout the human history. . The concept of grassroots economy endeavours in social equality and equal opportunity by putting decentralization in the core of economic activities. Altogether, it opens the space for cryptocurrencies and blockchain digital assets for small business entities to enable public growth [3]. In this article, the conventional public initiation of companies is reviewed which might be still useful for some less techy companies. The advantage of utilizing cryptocurrency as the better financial instrument is then being discussed.

\section{Sellout and IPO}

Growth of the company is bound with the shift from private ownership of the assets to the public. This is conventionally done either by the takeover of the private firm by the publicly traded firm (sellouts) or via Initial Public Offering (IPO).). There are indeed other types of raising capital such as borrowing money from bank and going in debt. However, since debt lays the foundation to financial slavery, this article shortens narration around borrowing. These two conventional types of transactions, being sellout and IPO, share a same set of attributes such as a significant shift in the ownership structure, a channel for raising capital, and a means of liquidation for owners. Yet, these attributes are unique for each type of transaction. IPOs allow the entity to remain independent, or in other words, the managerial board often continues to carry on the decision-making process. In contrast, sellouts permit the full control of the assets by the public company as the new owner. The structure of the transactions that move the assets to public ownership, also, are intrinsically different in a way that sellouts are free from the costly IPO process [4].

Private owners choose between sellout and IPO options. This decision is influenced externally by the synergies with the acquirer, the relative bargaining power of the private firm and the potential acquirer, and the presence of venture capitalists. Some internal (firm-specific) factors such as growth opportunities, financial constraints, and asymmetric information in firm valuation also affect the decision to choose between sellout and IPO. There is a cost associated with each type of move and the regulations are also different. From the drawbacks of IPOs one can refer to the cost of initial registration and continuing mandated disclosures, investment banking fees, and underpricing in the initial equity sale. The public firm to raise capital from a wide range of investors that they are associated with, is also incurred with another additional cost to convince the new investor about the value of the firm. Although there are almost similar costs in sellout moves, they are often lower than an IPO.

The private firm decides between sellout and IPO on the basis of growth opportunity that it sees and also the characteristics of its capital structure. Small construction business entities are typically 'capitalstarving' i.e. they consume financial capital and produce tangible assets such as buildings and infrastructure. Despite, public construction entities produce financial assets such as cash flow, future contracts, wages, etc. which are seen as economic motivations in the broader scale. Timing of which to take the private firm to public offering is done at the market peak [5]. One arguable point of view from the eyes of the parent company in the sellout process, is that those firms who decide to go with IPO are choosing so because they are operating in an economy with a lower opportunity to grow. This has 
been indicated by relying on the fact that choosing sellout option rather than IPO is associated with a higher associated risk as the managerial board of the small entity loses ground to the parent. And it is well articulated in the economic theories that higher risk is equivalent to higher gain in a healthy economy. In some cases, however, the managerial board of the small private firm maintains its control yet placed in the public firm to compete internally for scarce resources. In such situations, the private board prior to merge in the public firm must evaluate the other subsidiaries. However, competition is often destructive and thus cooperation is more recommended in these cases. IPOs in contrast to sellouts are somehow forced to set cooperation in their core value proposition. It is because through the IPO process the public sale of shares requires the firm to create and offer values to the market where other companies are at the same time nurtured. In fact, as the observation of growth opportunity precedes the IPO decision, cooperation is hopefully inevitable.

The move from private to public does also rely on the buyer and all other parties involved to gather accurate information about the small private firm. It is known that by the increase in the uncertainty of investors about the accuracy of the information, the cost of IPO valuation also increases. It is argued that in circumstances where the valuation is so difficult, the chance of private sellout rises which is the less favourite option in many cases. Still, subsidiaries of the parent public entity that serve the same function as the subject private entity can help in a faster IPO valuation. The internal financial structure of the private entity, indeed, plays an important role in the valuation process. In that essence, cash as the most desired type of asset is attractive to investors and the massive insolvent assets are the least favourite ones from the investors point of view. Often, providing accurate information requires a dedicated accounting department within the small business in addition to an independent auditing body to confirm the accuracy of the financial reports.

Overall, given the historic data and the current regulations, it is difficult to list a profitable public construction company which is ruled by the democratic laws. Australian Stock Exchange sets admission criteria for public listing of companies [6]. It is required from the firms who wish to be publicly listed to have a \$1 million aggregated profit from continuing operations over the past 3 years. Yet, when the historic data from the two giant Australian public construction firms with billions of dollar worth of capital is observed (Lendlease and Borals), a gross loss of about $20 \%$ in the share prices is recognized (figure). 


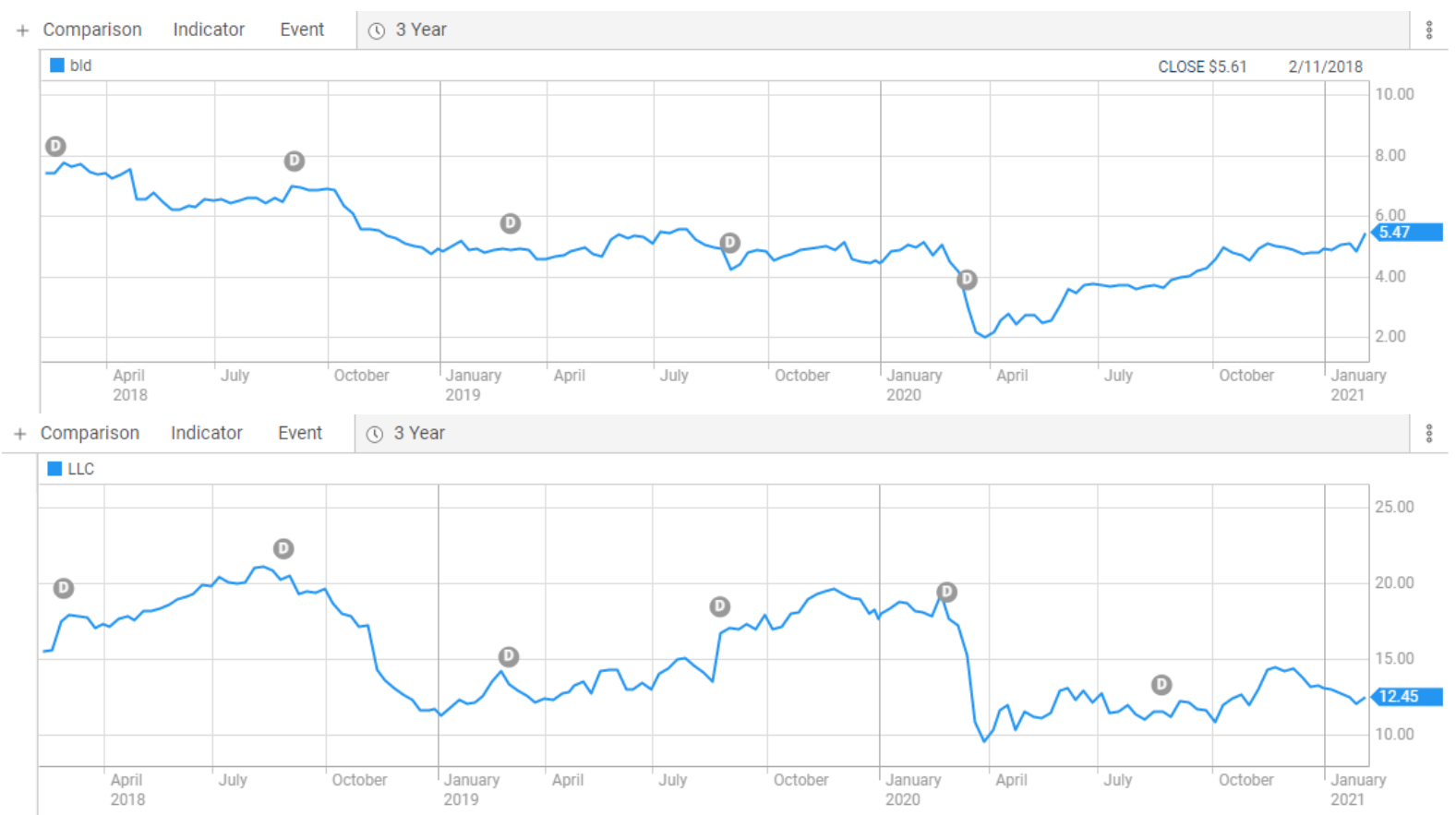

Figure 1 - Historic share prices of two giant construction public companies in the past 3 years (Top: Borals; Bottom: Lendlease)

In simple words, the current financial structure demands profit from the small businesses and return loss of capital after the company had been acquired publicly. The centralized financial malpractice is obvious. Small entities are encouraged by the centralized financial system, which lacks transparency, to list their business in the stock exchange and give up their managerial control with the hope of capital gain and business prosperity, yet the same system fails to realize its very core value proposition in the society that is the capital gain for businesses who wish to thrive. So, in today's world of business, IPO can be seen as a pitfall instead.

\section{Growth with cryptocurrency}

Considering the barriers to conventional IPOs caused by the highly regulated financial environment and the consequent social injustice, cryptocurrency as a new form of digital asset facilitates the company's growth. In the move from private to public, companies can issue a certain supply of their own cryptocurrency and trade their products and services based on this new currency. Like any other form of cash, it can be lent/borrowed to/from internal departments within the new public firm. Yet, public acceptance of the new cryptocurrency is still highly dependent on the network within which the company operates. There must be a public tendency to trade by the newly initiated crypto. Initial coin offering in an open market as such helps entrepreneurs to raise capital, create employment opportunity, and deliver their products and services to a broader community. The fast transfer of ownership of these digital assets enables the public company to spend more time on more important matters and customer satisfaction instead of wasting energy and time on useless conventional paperwork. Nevertheless, the acquisition of the crypto technology requires a good level of IT competency which might be absent in a large number of small construction businesses.

Adhami et al. [7] rationalizes the 'go to crypto' from three distinct standing points: (i) Adopting innovative technologies; (ii) Reduced cost of capital raising; (iii) Avoiding intermediaries and payment agents. Also, the freedom to create a secondary market is attractive to the eyes of managers if they are about to deepen financial control. It has been studied that the fundraising success rate using cryptocurrency is as high as $81 \%$ in a sample of 253 ICOs (Initial Coin Offering refers to the process of introducing new cryptocurrency) observed [7] in Canada, UK, Russia, and the US. Typically, ICOs require 
the disclosure of a document that contains a certain set of information such as IT protocol, adopted public blockchain, token supply, pricing and distribution mechanism, and details on the project to be developed (business plan and team description). Entrepreneurs can benefit from ICOs if only they commit to accept those tokens as payments for their products. In this way the demand for the newly invented currency thrives which in both classical and modern economic theories are considered crucial to the value of something. By offering a cryptocurrency, companies generate buyer competition which eventually creates value around the entity [8].

Based on underlying assets such as Bitcoin, Ethereum, and other tangible assets, the company can guarantee $10 \%$ annual interest rate to investors in the new crypto issued by the company. It can be rationalized by looking at the historic 2-years charts of Bitcoin and Ethereum (Figure 1) that had been appreciated roughly by about $700 \%$ and $900 \%$ respectively. For a truthful $\mathrm{ROI}$, the firm must consider appropriate and transparent terms upon issuing the guaranteed $10 \%$ interest. The proposed interest rate is competitive as well when it is compared to the current investment banking interest rates which are no more than $2 \%$ p.a.

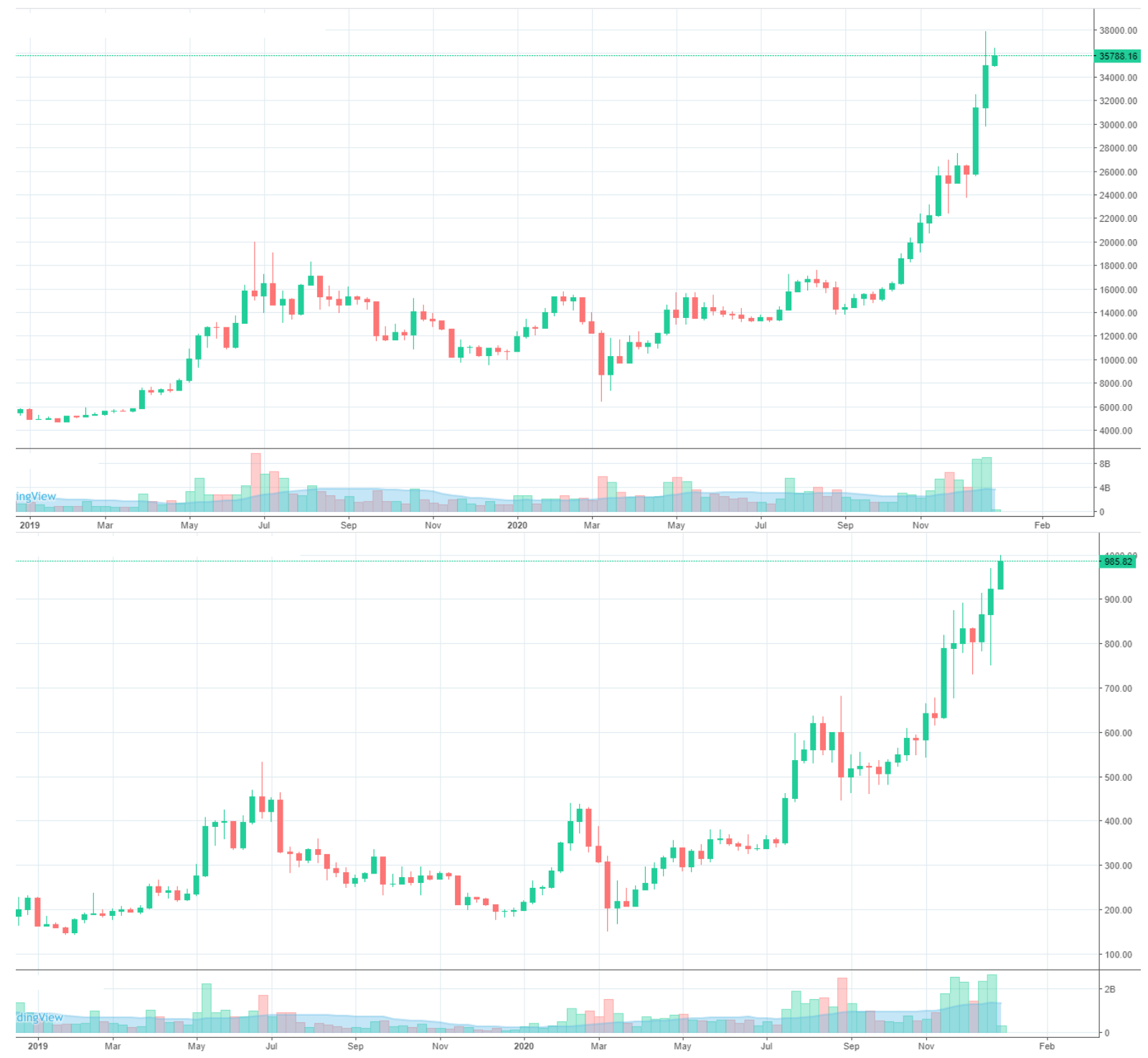

Figure 2 - Historic 2-year charts of Bitcoin and Ethereum as underlying assets to guarantee $10 \%$ annual interest rate to investors. 
Company's may choose to build the ICO on top of either Ethereum or Bitcoin blockchains. The results of a 2-month research practice reveals that Ethereum ecosystem is much more transparent and accessible than Bitcoin ecosystem. The already educational courses created by the Ethereum community shed light on a better future for Ethereum in terms of growth rate. ERC20, as an example, is a protocol that is designed for user friendliness.

\section{Initiation of Ethereum-based company-owned cryptocurrency}

As a major blockchain-based platform for smart contracts, Ethereum is executed on a decentralized peer-to-peer network. The main advantage of Ethereum protocol over other systems of blockchain is the suitability for implementing complex business logics [9]. As previously described, companies issue cryptos to raise capital through an ICO process. The most widely used token standard is Ethereum ERC20. This protocol defines technical specifications that allows the developers to program the way new tokens function within the Ethereum ecosystem [10].

In order to initiate the first company's ERC20 token, there are two requirements preceding. One, is the generation of tokens, and second, the wallet to store the tokens which also allows transactions to occur.

To initiate the new token in the Ethereum ecosystem the following ERC20 token contract had been adopted. The code imports two Ethereum smart contract libraries namely ERC20.sol and ERC20Detailed.sol to build the customized company token on top of the existing standards. The name, symbol, amount of supply, and the number of decimal places are defined. For testing purposes, an established Ethereum wallet for PC browsers named MetaMask is used. After compiling the codes locally, the snippet below must be deployed on the main Ethereum network and at the end, the tokens must be stored in a wallet for future transactions.

\section{ERC20 Token Construct}

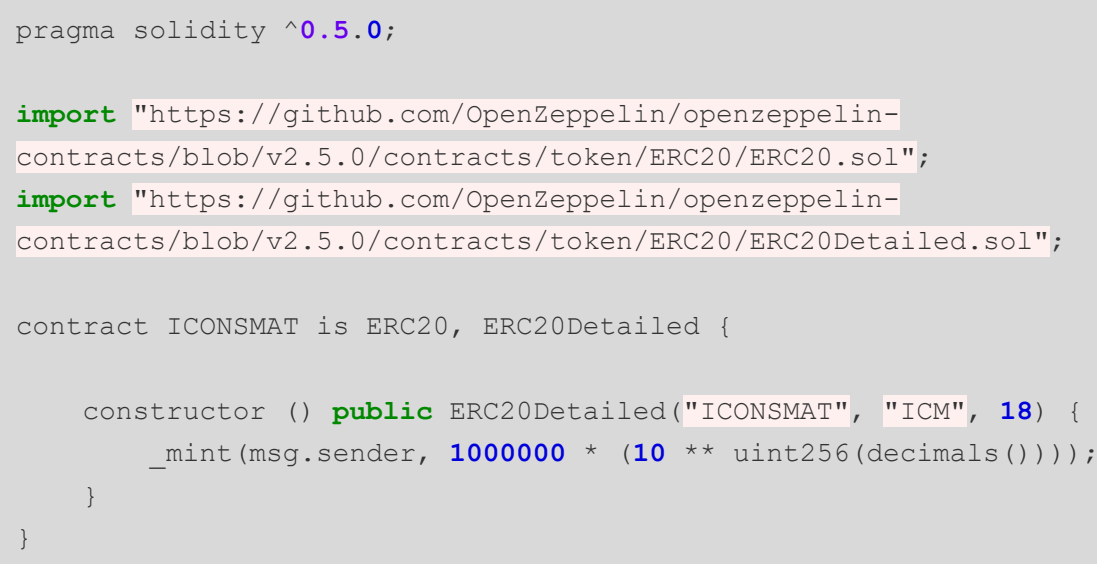

Figure 3 - Code snippet to generate the new cryptocurrency based on Ethereum blockchain.

During the course of this research, crypto tokens were made in a specified quantity of supply. However, the initial coin offering (white paper) is recommended to be made with a more in detailed set of consideration specially in regard to the timing and the market conditions. Certainly, before making the public offering, the private company that seeks to go public by introducing cryptocurrency as the means of raising capital, must ensure the existence of the demand from the customers perspective that enables them to pay for the company's goods and services. It is in this way that the value of the digital asset increases in the market. One of the most viable approaches for creating enough demand for the new coin is to reward customers with free coins every time they make a purchase of any kind. The coins can be accepted later upon the new purchase order. In some business-related literature, it is referred to as 'Loyalty Program' [11-13]. Once the customer is rewarded with the company owned 
cryptocurrency, the supply of money occurs. Along with the classical Keynesian economic theory, as supply emerges, demand will follow [14]. However, the excessive supply in comparison to the existing demand causes devaluation of the currency. So, the managerial board must be concerned about the timing and supply of the newly initiated coin in order to ensure the appreciation of the value.

With the green economy movement and other giant projects, researchers in the field of environmental construction must also put more focus on studying environmental alternatives for the existing nonenvironmental materials [15-34].

\section{Conclusion}

Construction small businesses that are seeking to grow and expand, often face multiple layers of frustrating regulations that if doesn't make the growth impossible, will put years of effort in front of the managers. This is mainly because the monopolies in the market tend to absorb these small entities. Yet, the principles of free open market and democratic rules protect social equality and prevent concentration of power which is proved to be corruptive. Thus, in this article, the initiation of company owned crypto assets as a promising way of growth had been disclosed. It's been recommended to have a precise attention on the timing to which the crypto asset is ought to be introduced to the public as it influences the success and price of the issued digital asset by a considerable amount. ERC20 protocol had been adopted which is an Ethereum based blockchain.

\section{Acknowledgment}

The authors declare the sole educational purpose of this article. Researchers interested in the proposed approach are highly encouraged to conduct independent research. All of the future research collaboration proposals in this area are more than welcome to the provided email addresses.

\section{References}

[1] J. Draho, The IPO decision: Why and how companies go public. Edward Elgar Publishing, 2004.

[2] G. M. Hodgson, "Capitalism, complexity, and inequality," Journal of Economic Issues, vol. 37, no. 2, pp. 471-478, 2003.

[3] A. Šapkauskienė and I. Višinskaitè, "Initial Coin Offerings (ICOs): benefits, risks and success measures," Entrepreneurship and sustainability issues, vol. 7, no. 3, pp. 1472-1483, 2020.

[4] A. B. Poulsen and M. Stegemoller, "Moving from private to public ownership: selling out to public firms versus initial public offerings," Financial Management, vol. 37, no. 1, pp. 81-101, 2008.

[5] J. Lerner, "Venture capitalists and the decision to go public," Journal of financial Economics, vol. 35, no. 3, pp. 293-316, 1994.

[6] E. Grieve, J. Posnett, and K. Galpin. "Public listing requirments." Australian Stock Exchange (ASX). https://www2.asx.com.au/listings/how-to-list/listing-requirements (accessed.

[7] S. Adhami, G. Giudici, and S. Martinazzi, "Why do businesses go crypto? An empirical analysis of initial coin offerings," Journal of Economics and Business, vol. 100, pp. 64-75, 2018.

[8] C. Catalini and J. S. Gans, "Initial coin offerings and the value of crypto tokens," National Bureau of Economic Research, 0898-2937, 2018.

[9] S. Tikhomirov, "Ethereum: state of knowledge and research perspectives," in International Symposium on Foundations and Practice of Security, 2017: Springer, pp. 206-221.

[10] S. Somin, G. Gordon, A. Pentland, E. Shmueli, and Y. Altshuler, "ERC20 Transactions over Ethereum Blockchain: Network Analysis and Predictions," arXiv preprint arXiv:2004.08201, 2020. 
[11] K. Bridson, J. Evans, and M. Hickman, "Assessing the relationship between loyalty program attributes, store satisfaction and store loyalty," Journal of Retailing and consumer Services, vol. 15, no. 5, pp. 364374, 2008.

[12] B. Berman, "Developing an effective customer loyalty program," California management review, vol. 49, no. 1, pp. 123-148, 2006.

[13] Y. Yi and H. Jeon, "Effects of loyalty programs on value perception, program loyalty, and brand loyalty," Journal of the academy of marketing science, vol. 31, no. 3, pp. 229-240, 2003.

[14] J. M. Keynes, The general theory of employment, interest, and money. Springer, 2018.

[15] F. Sartipi, "Automatic sorting of recycled aggregate using image processing and object detection," Journal of Construction Materials, vol. 1, pp. 3-3, 2020, doi: https://doi.org/10.36756/JCM.v1.2.1.

[16] F. Sartipi, "A brief critical view on the carbon-conditioning of recycled aggregate using pressure chamber," Journal of Construction Materials, vol. 2, pp. 1-4, 2020, doi: https://doi.org/10.36756/JCM.v2.1.4.

[17] F. Sartipi and A. Sartipi, "Brief review on advancements in construction additive manufacturing," Journal of Construction Materials, vol. 1, pp. 2-4, 2020, doi: https://doi.org/10.36756/JCM.v1.2.4

[18] F. Sartipi, "Diffusion of Innovation Theory in the Realm of Environmental Construction," Journal of Construction Materials, vol. 1, pp. 4-2, 2020, doi: https://doi.org/10.36756/JCM.v1.3.2.

[19] F. Sartipi, "Dynamic data processing for building energy consumption," Journal of Construction Materials, vol. 2, no. 2021, pp. 2-4, 2020, doi: https://doi.org/10.36756/JCM.v2.2.4.

[20] F. Sartipi, "Influence of $5 \mathrm{G}$ and IoT in construction and demolition waste recycling-conceptual smart city design," Journal of Construction Materials, vol. 1, pp. 4-1, 2020, doi: https://doi.org/10.36756/JCM.v1.4.1.

[21] F. Sartipi, "Organizational structure of construction entities based on the cooperative game theory," Journal of Construction Materials, vol. 1, no. 2, 2020, doi: https://doi.org/10.36756/JCM.v1.3.3

[22] A. Kandiri, F. Sartipi, and M. Kioumarsi, "Predicting Compressive Strength of Concrete Containing Recycled Aggregate Using Modified ANN with Different Optimization Algorithms," Applied Sciences, vol. 11, no. 2, p. 485, 2021, doi: https://doi.org/10.3390/app11020485.

[23] F. Sartipi, "Preliminary structural design for extraterrestrial buildings," Journal of Construction Materials, vol. 2, pp. 2-3, 2021, doi: https://doi.org/10.36756/JCM.v2.2.3.

[24] M. Sartipi and F. Sartipi, "Stormwater retention using pervious concrete pavement: Great Western Sydney case study," Case Studies in Construction Materials, vol. 11, p. e00274, 2019.

[25] F. Sartipi, K. Palaskar, A. Ergin, and U. Rajakaruna, "Viable construction technology for habitation on Mars: Fused Deposition Modelling," Journal of Construction Materials, vol. 1, no. 2, 2020.

[26] A. Kandiri and F. Fotouhi, "Predicting the creep coefficient of green concretes containing ground granulated blast furnace slag using hybridized multi-objective ANN and Salp swarm algorithm," Journal of Construction Materials, vol. 2, no. 2021, pp. 2-1, 2020.

[27] A. Kandiri and F. Fotouhi, "Prediction of the module of elasticity of green concretes containing ground granulated blast furnace slag using hybridized multi-objective ANN and Salp swarm algorithm," Journal of Construction Materials, vol. 2, no. 2021, pp. 2-2, 2020.

[28] X. Gong, Q. Liu, G. Ye, Q. Xiang, and Y. Wang, "Analyzing the impact of group norms on workers' safety behaviors in a construction team," in International Conference on Applied Human Factors and Ergonomics, 2018: Springer, pp. 598-605.

[29] Q. Liu, Y. Feng, and K. London, "Conceptual model for managing mental health in the culturally diverse construction workforce," in Proceedings of the Thirty-sixth Annual Conference of the Association of Researchers in Construction Management (ARCOM), September 7-8, 2020, UK, 2020, pp. 595-604.

[30] G. Ye, Q. Tan, X. Gong, Q. Xiang, Y. Wang, and Q. Liu, "Improved HFACS on Human Factors of Construction Accidents: A China Perspective," Advances in Civil Engineering, vol. 2018, 2018.

[31] J. Yang, G. Ye, Q. Xiang, M. Kim, Q. Liu, and H. Yue, "Insights into the mechanism of construction workers' unsafe behaviors from an individual perspective," Safety Science, vol. 133, p. 105004, 2021.

[32] Q. Xiang, X. Gong, G. Ye, Q. Liu, and Y. Wang, "Modeling the Effect of Group Norms on Construction Workers' Safety Behavior," in ICCREM 2018: Construction Enterprises and Project Management: American Society of Civil Engineers Reston, VA, 2018, pp. 238-244.

[33] Y. Fu, G. Ye, X. Tang, and Q. Liu, "Theoretical Framework for Informal Groups of Construction Workers: A Grounded Theory Study," Sustainability, vol. 11, no. 23, p. 6769, 2019.

[34] Q. Liu, G. Ye, and Y. Feng, "Workers' safety behaviors in the off-site manufacturing plant," Engineering, Construction and Architectural Management, 2019. 